\title{
Using the Nordic Geodetic Observing System for land uplift studies
}

\author{
M. Nordman ${ }^{1}$, M. Poutanen ${ }^{1}$, A. Kairus ${ }^{1,2}$, and J. Virtanen ${ }^{1}$ \\ ${ }^{1}$ Finnish Geodetic Institute, P.O. Box 15, 02431 Masala, Finland \\ ${ }^{2}$ Aalto University, Espoo, Finland \\ Correspondence to: M. Nordman (maaria.nordman@fgi.fi) \\ Received: 9 January 2014 - Published in Solid Earth Discuss.: 30 January 2014 \\ Revised: 12 May 2014 - Accepted: 13 May 2014 - Published: 17 July 2014
}

\begin{abstract}
Geodetic observing systems have been planned and developed during the last decade. An ideal observing system consists of a network of geodetic observing stations with several techniques at the same site, publicly accessible databases, and as a product delivers data time series, combination of techniques or some other results obtained from the data sets. Globally, there is the International Association of Geodesy (IAG) Global Geodetic Observing System (GGOS), and there are ongoing attempts to create also regional observing systems. In this paper we introduce one regional system, the Nordic Geodetic Observing System (NGOS) hosted by the Nordic Geodetic Commission (NKG).

Data availability and accessibility are one of the major issues today. We discuss in general data-related topics, and introduce a pilot database project of NGOS. As a demonstration of the use of such a database, we apply it for postglacial rebound studies in the Fennoscandian area. We compare land uplift values from three techniques, GNSS, tide gauges and absolute gravity, with the Nordic Geodetic Commission NKG2005LU land uplift model for Fennoscandia. The purpose is to evaluate the data obtained from different techniques and different sources and get the most reliable values for the uplift using publicly available data.

The primary aim of observing systems will be to produce data and other products needed by multidisciplinary projects, such as Upper Mantle Dynamics and Quaternary Climate in Cratonic Areas (DynaQlim) or the European Plate Observing System (EPOS), but their needs may currently exceed the scope of an existing observing system. We discuss what requirements the projects pose to observing systems and their development. To make comparisons between different studies possible and reliable, the researcher should document what they have in detail, either in appendixes, supplementary material or some other available format.
\end{abstract}

\section{Introduction}

Permanent geodetic observing networks have been developed during the last decade to become the basic component of geodetic observing systems. The observing systems aim to provide better and more detailed information on the global and regional gravity field, its temporal variation, crustal deformation, global changes in Earth's shape, mass distribution, sea level, and the Earth orientation in the inertial frame. An ideal observing system consists of geodetic observing stations with several techniques at the same site, publicly accessible databases, and as products, data and combination of different observing techniques. An ideal observing system also has a carefully documented database, where all information related to measurements, modelling, products and other subtleties is stored.

Globally, the International Association of Geodesy Global Geodetic Observing System (IAG GGOS) is based on existing IAG Service; see (http://www.iag-aig.org/) for details and access points to the services and their products. Status and goals are described in Plag and Pearlman (2009). Parallel to the development of GGOS, regional systems have been discussed and initiated. These include the European Combined Geodetic Network (ECGN) by the IAG Reference Frame Sub-Commission 1.3a for Europe (EUREF; Ihde et al., 2004; Poutanen et al., 2014), and the Nordic Geodetic Observing System (NGOS) of the Nordic Geodetic Commission (NKG; Poutanen et al., 2005, 2007).

Observing systems produce data and other products which are typically combinations of different techniques, where the observed signals can be a mixture of several underlying geophysical processes. For example, height changes are measured by GNSS and related gravity changes by repeated gravity measurements. Mass changes are not visible in GNSS 
data, whereas the observed gravity change is the sum of mass and height changes. The combination of techniques can verify results of a single technique and help to quantify uncertainties between the techniques and help us to understand physical processes behind changes (e.g. Poutanen et al., 2010).

There are several ongoing initiatives which need such high-quality multi-technique data. As an example, we mention two: Upper Mantle Dynamics and Quaternary Climate in Cratonic Areas (DynaQlim; Poutanen et al., 2010), and European Plate Observing System (EPOS; http://www.epos-eu. org/). EPOS is an integrated solid Earth sciences research infrastructure approved by the European Strategy Forum on Research Infrastructures (ESFRI) and included in the ESFRI Roadmap. DynaQlim is a regional coordination committee of the International Lithosphere Program (ILP) and studies upper mantle dynamics, its composition and physical properties (temperature and rheology), and Quaternary climate primarily on Fennoscandia, northern Canada and Antarctica.

Specific data needs of such research may exceed the scope of an existing observing system, and this raises the issue of observing system product development. As an example of such dialogue, a joint meeting of GGOS and DynaQlim was organized in 2009 in Espoo, Finland (Gross and Poutanen, 2009). One of the goals was to discuss what specific data or products DynaQlim may expect from GGOS and what possibilities GGOS has to fulfill such requirements. An obvious shortcoming of GGOS is the density of the observing network. It is too sparse for regional studies, and there is a need for denser regional observing networks.

One of the major geodynamic processes acting in Fennoscandia and northern Canada is the land uplift caused by glacial isostatic adjustment (GIA). GIA is the response of the solid Earth to the time-varying load due to the waxing and waning of glaciers, causing sea level to vary by up to $130 \mathrm{~m}$ in cycles of $\sim 100000$ years. Taking into account the mass change between oceans and glaciers and upper mantle viscoelastic flow, there is a total of $5 \times 10^{19} \mathrm{~kg}$ of mass transportation during the glaciation cycle (almost $10^{-5}$ of the mass of the Earth; e.g. van Dam et al., 2008; Poutanen and Ivins, 2010).

The GIA signal, however, is contaminated by non-GIAinduced mass changes and crustal deformation. Separating GIA-induced contributions from other sources is not straightforward and using data from a geodetic observing system with multiple techniques can help in this task. However, the global network of GGOS is not sufficient to observe GIA in detail because in the Fennoscandian rebound area there are only half a dozen GGOS stations. In northern Canada, the number of stations is even smaller.

An improvement is to include permanent stations of a regional network. In Fennoscandia, there exists the NGOS network, which contains the Nordic geodetic permanent GPS/GNSS stations (Poutanen et al., 2005, 2007) operated by the national mapping authorities. Mass change can be es-

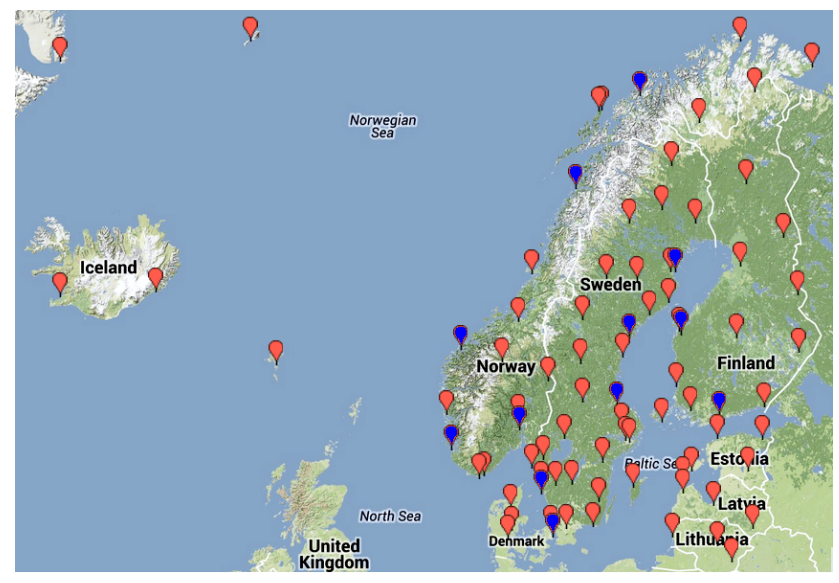

Figure 1. The stations in the NGOS database. The blue dots show the stations chosen for the comparison (see text, names of stations are shown in Fig. 3). Map: Google.

timated from the gravity change which is monitored by repeated measurements by absolute gravimeters and combined with the height change data given by GPS. A step further is the EPOS which is planned to be an open access infrastructure serving as primary source of data and tools for researchers in geosciences (http://www.epos-eu.org/).

It is important to test the capability of current observing systems and regional networks, databases and other sources of information in GIA-related studies. The EUREF Technical Working Group decided in 2011 to propose a pilot project within the ECGN (Poutanen et al., 2014). The project is meant to demonstrate the ideas and usefulness of a regional observing system in utilizing existing networks and databases. The ECGN network consists mostly of EPN (EUREF Permanent GNSS Network) stations, which especially in Fennoscandia are too sparse for detailed studies of regional crustal deformation.

A suitable network for such studies already exists in Fennoscandia as a result of the NKG NGOS task force in the period 2004-2010 (Poutanen et al., 2005, 2007) and its follow-on pilot project Nordic Combined Geodetic Network (NCGN).

As a part of the NCGN project, we have collected information of geodetic stations in the Fennoscandian and Baltic areas into a database using mostly the NGOS stations (Kairus, 2012). We describe the data in Sect. 2, comparison of different techniques and discussion of results are presented in Sect. 3, and Sect. 4 is left for conclusions.

\section{Selection of data and previously published studies}

The existing list of NGOS stations (Poutanen et al., 2005) was taken as the starting point. We created an interface which contains metadata for those stations and links to different geodetic databases. The interface can be found on the 


Metsähovi
\begin{tabular}{|l|l|}
\hline Station name & Metsähovi \\
\hline Latitude & 60.218 \\
\hline Longitude & 24.395 \\
\hline Height (m) & 95 \\
\hline Country & Finland \\
\hline GNSS & EPN IGS SONEL \\
\hline SLR & ILRS \\
\hline DORIS & IDS \\
\hline Gravity & GGP Station data Absolute Gravity data BGI \\
\hline VLBI & EVLBI IVS \\
\hline Local tie & - \\
\hline Levelling & - \\
\hline Tide gauge & - \\
\hline
\end{tabular}

Figure 2. Database entry for station Metsähovi, containing station coordinates, and links to various databases with observations from Metsähovi.

NKG web pages (http://www.nkg.fi $\rightarrow$ NKG Data Banks). The station list database is also available as a clickable map interface (Fig. 1). For each station a page with station information and links to relevant databases was created (Fig. 2). The links include GNSS databases (The International GNSS Service (IGS; http://igscb.jpl.nasa.gov/), EUREF Permanent Network (EPN; http://www.epncb.oma.be/) and SONEL (http://www.sonel.org)), gravity databases in the Global Geodynamics Project (GGP; http://www.eas.slu.edu/ GGP/ggphome.html) and the International Gravimetric $\mathrm{Bu}-$ reau (BGI; http://bgi.omp.obs-mip.fr/), tide gauge databases in the Permanent Service for Mean Sea Level (PSMSL; http://www.psmsl.org/) and SONEL, and databases of VLBI (Very Long Baseline Interferometry), SLR (Satellite Laser Ranging) and DORIS (Doppler Orbitography and Radiopositioning Integrated by Satellite) of respective IAG/GGOS services (http://www.ggos.org/ $\rightarrow$ Products). In addition to data, links to relevant research papers are given.

To demonstrate and study the usefulness of the database to study GIA-induced land uplift, we have chosen 12 stations. They are all located at the coast, have permanent GNSS stations with absolute gravity measurements and are in the vicinity of a tide gauge. The locations are shown in Fig. 1 with blue dots.

There have been numerous campaigns and observations in Fennoscandia for land uplift studies using different techniques together and separately. Land uplift data from several previously published sources are collected here but there are several nuisances which are not properly handled. For example, tide gauge heights are orthometric, whereas GNSS refer to the ellipsoidal heights. Different techniques refer to different points, for example GNSS height refers either to the antenna or a benchmark on the ground whereas gravity is measured on a different point. Local ties are incomplete at most stations. A step forward was taken in the first science week of NKG in Reykjavik, March 2013, where its development was decided and then taken in use by the working groups of the NKG.

\subsection{GNSS data}

GNSS provides three-dimensional coordinates, where the station height is given above the ellipsoid. The time series and land uplift rates derived from the BIFORST (Baseline Inferences for Fennoscandian Rebound, Sea-level, and Tectonics) GPS studies have the densest spatial coverage of all techniques at the moment. The stations have been operational since the mid-1990s, thus offering time series of almost 20 years. There are several studies published, the first one by Johansson et al. (2002). The next generation of uplift rates were published in Lidberg et al. (2007), and the latest update in Lidberg et al. (2010). Uplift rates from GNSS time series can be seen in the first part of Table 1 . We have chosen the results of Lidberg et al. (2010) (in italic in Table 1) for the comparison because the time series are the longest (maximum 10.2 years) and the spatial coverage (with 85 stations) is the largest. GNSS processing software has been markedly developed, making it possible to recompute satellite orbits in a unified reference frame and, in turn, giving a more consistent solution over the years. These are also in favour of choosing the latest solution. Uncertainty of the uplift value based on the GNSS time series depends mostly on the length of time series; temporal correlations may cause the error to reduce slower. For stations with long time series, the uncertainty is $0.2 \mathrm{~mm} \mathrm{yr}^{-1}$, whereas for other stations the uncertainty is approximately $0.5 \mathrm{~mm} \mathrm{yr}^{-1}$ (Lidberg et al., 2010).

\subsection{Absolute gravity data}

Gravity changes provide information on mass changes related to the land uplift. The gravity change can be converted to height change by using a simple ratio, limited by theoretically computed bounds, and derived from observations:

$\dot{g} / \dot{h}=-0.17 \mu \mathrm{Gal} \mathrm{mm}^{-1}$,

where $\dot{g}$ is the gravity change and $\dot{h}$ is the height change (e.g. Ekman and Mäkinen, 1996). The ratio has been evaluated from different data sets yielding slightly different values, e.g. $-0.163 \pm 0.02$ (Gitlein, 2010), -0.16 and $-0.20 \mu \mathrm{Gal} \mathrm{mm}^{-1}$ (Mäkinen et al., 2005). Our value falls within this range.

There have been several campaigns with numerous absolute and relative gravimeters during the last decades in the Fennoscandian area. For this study, we have chosen the latest published absolute gravity values from Pettersen (2011), Gitlein (2010) and Breili (2009). The values (in $\mu \mathrm{Gal} \mathrm{yr}^{-1}$ ) are shown in the second part of Table 1 . The observed sites are different in each paper and some stations show more consistent values. For Tables 2 and 3 these values are converted to millimetres per year using formula (1). The error 
Table 1. Trend estimates of all techniques and different sources for the selected sites (see Fig. 1). AG is absolute gravity, TG is tide gauge. In italic are the values chosen for each station for comparison. Model is the NKG2005LU uplift model.

\begin{tabular}{|c|c|c|c|c|c|c|c|c|c|c|}
\hline \multirow[t]{2}{*}{ Station } & \multicolumn{3}{|c|}{ GNSS $\left(\mathrm{mm} \mathrm{yr}^{-1}\right)$} & \multicolumn{3}{|c|}{$\mathrm{AG}\left(\mu \mathrm{Gal} \mathrm{yr}^{-1}\right)$} & \multicolumn{3}{|c|}{$\mathrm{TG}\left(\mathrm{mm} \mathrm{yr}^{-1}\right)$} & \multirow{2}{*}{$\begin{array}{c}\begin{array}{c}\text { Model } \\
\left(\mathrm{mm} \mathrm{yr}^{-1}\right)\end{array} \\
\text { Vestøl } \\
2005\end{array}$} \\
\hline & $\begin{array}{l}\text { Lidberg } \\
2010\end{array}$ & $\begin{array}{c}\text { Lidberg } \\
2007\end{array}$ & $\begin{array}{c}\text { Johansson } \\
2002\end{array}$ & $\begin{array}{c}\text { Gitlein } \\
2010\end{array}$ & $\begin{array}{c}\text { Pettersen } \\
2011\end{array}$ & $\begin{array}{l}\text { Breili } \\
2009\end{array}$ & PSMSL & GIA-RSL & $\begin{array}{c}\text { Ekman } \\
1998\end{array}$ & \\
\hline Metsähovi & 5.21 & 4.26 & 5.4 & -0.88 & -0.5 & & -2.08 & -2.02 & -2.28 & 2.59 \\
\hline Vaasa & 9.28 & 8.62 & 10.7 & -1.22 & -2.2 & & -7.11 & -8.66 & -7.62 & 7.19 \\
\hline Skellefteå & 10.95 & 9.61 & 10.7 & -1.88 & -1.8 & & -8.25 & -9.63 & -8.75 & 7.84 \\
\hline Kramfors & 10.11 & 9.24 & 10 & -1.44 & & & -6.38 & -8.01 & -7.57 & 7.6 \\
\hline Mårtsbo & 8.86 & 6.74 & 7.3 & -1.56 & -1.2 & & -5.94 & -6.52 & -5.9 & 5.63 \\
\hline Copenhagen & 1.26 & -0.24 & & 0.19 & & & 0.6 & -0.26 & 0.24 & -0.39 \\
\hline Onsala & 4.05 & 2.66 & -0.4 & 0.5 & -0.8 & & 0.32 & -1.85 & -1.99 & 0.84 \\
\hline Oslo & 6.51 & 5.78 & & & & -0.6 & -3.75 & -4.33 & -4.1 & 2.86 \\
\hline Stavanger & 2.9 & 1.18 & & & -0.1 & -0.2 & 0.37 & -1.14 & 0.19 & -0.39 \\
\hline Ålesund & 3.72 & & & & & -0.4 & 0.82 & -0.85 & & 0.22 \\
\hline Bod $\varnothing$ & 6.39 & & & & & -0.5 & -1.23 & -1.56 & & 2.15 \\
\hline Troms $\emptyset$ & 4.15 & 2.3 & 4 & & -0.2 & -0.5 & -0.02 & -1.16 & -3.06 & 0.95 \\
\hline
\end{tabular}

Table 2. Comparison of uplift trends for different techniques. AG is absolute gravity converted using formula (1), TG is tide gauge and Model represents the NKG2005LU uplift model values converted to the absolute uplift values using Eq. (2). Here we use the eustatic sea level rise of $1.32 \mathrm{~mm} \mathrm{yr}^{-1}$. Mean is the mean value of four techniques and SD is the standard deviation.

\begin{tabular}{lcccccc}
\hline Station & GNSS & AG & TG & Model & Mean & SD \\
\hline Metsähovi & 5.21 & 5.18 & 3.62 & 4.16 & 4.54 & 0.79 \\
Vaasa & 9.28 & 7.18 & 8.97 & 9.05 & 8.62 & 0.97 \\
Skellefteå & 10.95 & 11.06 & 10.18 & 9.74 & 10.48 & 0.63 \\
Kramfors & 10.11 & 8.47 & 8.19 & 9.49 & 9.07 & 0.89 \\
Mårtsbo & 8.86 & 9.18 & 7.72 & 7.39 & 8.29 & 0.86 \\
Copenhagen & 1.26 & -1.12 & 0.77 & 0.99 & 0.47 & 1.08 \\
Onsala & 4.05 & 4.71 & 1.06 & 2.30 & 3.03 & 1.66 \\
Oslo & 6.51 & 3.53 & 5.39 & 4.45 & 4.97 & 1.28 \\
Stavanger & 2.90 & 1.18 & 1.01 & 0.99 & 1.52 & 0.92 \\
Ålesund & 3.72 & 2.35 & 0.53 & 1.64 & 2.06 & 1.34 \\
Bodø & 6.39 & 2.94 & 2.71 & 3.69 & 3.93 & 1.69 \\
Troms $\varnothing$ & 4.15 & 2.94 & 1.43 & 2.41 & 2.73 & 1.13 \\
\hline
\end{tabular}

of the absolute gravity measurements has been estimated to be $\pm 0.3 \mu \mathrm{Gal} \mathrm{yr}^{-1}$ (Timmen et al., 2011) for one instrument over 5 years. This corresponds to an error of $\pm 1.8 \mathrm{~mm} \mathrm{yr}^{-1}$ in the uplift value.

\subsection{Tide gauge data}

Tide gauges measure the sea level relative to land and provide the longest continuous geodetic time series in the Fennoscandia. The water column records start already in 1774 in Stockholm and there are tide gauges in the area dating back to the end of the 19th century. There are several sources for the tide gauge data; we have used tide gauge trends derived in Peltier (1998, 2004), Ekman (1998) and Woodworth and Player (2004).

The trends of the Permanent Service for Mean Sea Level (PSMSL, Woodworth and Player, 2004) are the apparent mean sea level secular trends derived from PSMSL data with all available observations for each station. These trends were updated in 2014 and refer to the revised local reference (RLR; http://www.psmsl.org/products/trends/trends. txt). Glacial isostatic-adjustment-corrected relative sea level trends (GIA-RSL) are the apparent sea level trends predicted from Peltier's GIA model (Peltier, 1998, 2004). The third set of trends are the values from Ekman (1998), which combine levelling and tide gauge data to define the sea level rise. We choose the PSMSL secular trends for the present comparison (Table 1), because they are not affected by other techniques (e.g. GIA model or fitting of data).

There are three different cases of uplift values which can be observed. From the GNSS time series one obtains the absolute uplift: height change of the crust relative to the mass centre of the Earth (origin of the global reference frame). With a tide gauge, one observes the apparent uplift value, i.e. change of the sea level relative to the shoreline. The relative uplift is the difference of the apparent uplift rates between two tide gauges. The apparent uplift differs from the absolute uplift due to the global eustatic sea level rise, rise of the geoid, as well as steric effects (salinity and density changes due to the thermal expansion). The relation between these is (Mäkinen et al., 2005)

$\dot{h}=\dot{H}_{\mathrm{a}}+\dot{H}_{\mathrm{e}}+\dot{N}+\dot{H}_{\mathrm{s}}$,

where $\dot{h}$ is the absolute uplift rate, $\dot{H}_{\mathrm{a}}$ is the apparent uplift, $\dot{H}_{\mathrm{e}}$ the eustatic rise of the sea level, $\dot{N}$ is the rise of the geoid, and $\dot{H}_{\mathrm{S}}$ denotes possible changes in steric effects. The last one is often neglected. 
Table 3. Comparison of uplift trends for different techniques. AG is absolute gravity converted using formula (1), TG is tide gauge and Model represents the NKG2005LU uplift model values converted to the absolute uplift values using Eq. (2). We use here the eustatic sea level rise of $3.11 \mathrm{~mm} \mathrm{yr}^{-1}$. Mean is the mean value of four techniques and SD is the standard deviation. Mean2 and SD2 are computed without the absolute gravity values (see text).

\begin{tabular}{lcccccccc}
\hline Station & GNSS & AG & TG & Model & Mean & SD & Mean2 & SD2 \\
\hline Metsähovi & 5.21 & 5.18 & 5.65 & 5.98 & 5.50 & 0.38 & 5.61 & 0.39 \\
Vaasa & 9.28 & 7.18 & 10.85 & 10.87 & 9.55 & 1.74 & 10.33 & 0.91 \\
Skellefteå & 10.95 & 11.06 & 11.84 & 11.56 & 11.35 & 0.42 & 11.45 & 0.46 \\
Kramfors & 10.11 & 8.47 & 9.67 & 11.31 & 9.89 & 1.17 & 10.36 & 0.85 \\
Mårtsbo & 8.86 & 9.18 & 9.65 & 9.21 & 9.23 & 0.32 & 9.24 & 0.40 \\
Copenhagen & 1.26 & -1.12 & 2.56 & 2.81 & 1.38 & 1.80 & 2.21 & 0.83 \\
Onsala & 4.05 & 4.71 & 2.67 & 4.12 & 3.89 & 0.86 & 3.61 & 0.82 \\
Oslo & 6.51 & 3.53 & 6.60 & 6.27 & 5.73 & 1.47 & 6.46 & 0.17 \\
Stavanger & 2.90 & 1.18 & 2.79 & 2.81 & 2.42 & 0.83 & 2.83 & 0.06 \\
Ålesund & 3.72 & 2.35 & 2.37 & 3.46 & 2.97 & 0.72 & 3.18 & 0.71 \\
Bod $\varnothing$ & 6.39 & 2.94 & 4.45 & 5.51 & 4.82 & 1.48 & 5.45 & 0.97 \\
Troms $\varnothing$ & 4.15 & 2.94 & 3.26 & 4.23 & 3.64 & 0.65 & 3.88 & 0.54 \\
\hline
\end{tabular}

In Tables 2 and 3, the tide gauge values are corrected for the eustatic sea level rise using two different estimates, respectively; see the next section for discussion. With the value of 0.2 (Ekman, 1998) and 0.1-0.7 $\mathrm{mm} \mathrm{yr}^{-1}$ (PSMSL) the uncertainty estimates of the tide gauge trends are the lowest of the compared techniques, since the time series are the longest.

\subsection{NKG2005LU model}

The NKG2005LU land uplift model (Vestøl, 2005, Ågren and Svensson, 2007), which was initiated and computed in the NKG working group for height determination, is used widely for practical applications in the Nordic countries. It is an empirical model leaning on the repeated levellings of Finland, Sweden and Norway. The observations used for the model stem mainly from two sources. Tide gauge and levelling values are taken from Ekman (1996) and GNSS values are from Lidberg (2004) and Lidberg et al. (2007). These data have been used to interpolate and extrapolate a continuous surface for land uplift. For areas where observational data are sparse or missing, the GIA model values from Lambeck et al. (1998) have been used; for example, for the Russian Karelian area behind the east border of Finland.

\section{Comparison and discussion}

The land uplift values obtained from the individual techniques for the 12 stations chosen are given in Tables 2 and 3. Tide gauge and NKG2005LU values refer to the apparent sea level change and thus need to be converted to the absolute uplift rate using a fixed value for the eustatic sea level rise in Eq. (2). The geoid rise due to the uplift is about $6 \%$ of the uplift value near the centre of the uplift maximum (Ekman and Mäkinen, 1996). We used this value in Eq. (2) for the geoid rise. The steric effects were ignored because they cannot be estimated and they are presumably small.

We give two sets of trend estimates which we computed assuming two different values for the sea level rise. In Table 2, the sea level rise has been taken to be $1.32 \mathrm{~mm} \mathrm{yr}^{-1}$, which is the value used in the NKG2005LU model (Vest $\varnothing 1$, 2005). For Table 3, we have estimated the sea level rise by computing the mean absolute sea level value from our data set (see Eq. 3). The mean and standard deviation of the trend estimates at each station have also been computed.

The results in Table 2 show the well-known pattern of high uplift rates at the Gulf of Bothnia (Vaasa, Skellefteå, Kramfors) with gradually falling values towards the edges of the rebound area. The NKG2005LU model shows quite low values for the Norwegian sites compared to the latest GNSS solution. This is most likely due to the fact that in the model the older version of BIFROST solutions (Lidberg et al., 2007) were used and these old values include only Swedish and Finnish sites. The standard deviations for the stations range from 0.6 (Skellefteå) to $1.7 \mathrm{~mm} \mathrm{yr}^{-1}$ (Onsala and Bodø), indicating more stable land uplift trends on the Baltic Sea, while more variability is seen on the Atlantic coast and Danish straits. The mean of the standard deviations is $1.1 \mathrm{~mm} \mathrm{yr}^{-1}$. The values of Table 2 are depicted in Fig. 3 .

The contemporary global sea level rise is known to be about $3 \mathrm{~mm} \mathrm{yr}^{-1}$ (e.g. Cazenave and Llovel, 2010; Church et al., 2013) which is considerably more than the value used in the NKG2005LU model. The lower value was based on the mean sea level rise in the Baltic Sea in the period 18911990 (Vestøl, 2005). For Table 3, a new value of the sea level rise was computed as a mean of the chosen stations:

$\dot{H}_{\mathrm{e}}=\frac{1}{n} \sum_{i=1}^{n}\left\{\left(\dot{h}_{i} \times 0.94\right)-\dot{H}_{\mathrm{a}, i}\right\}$, 


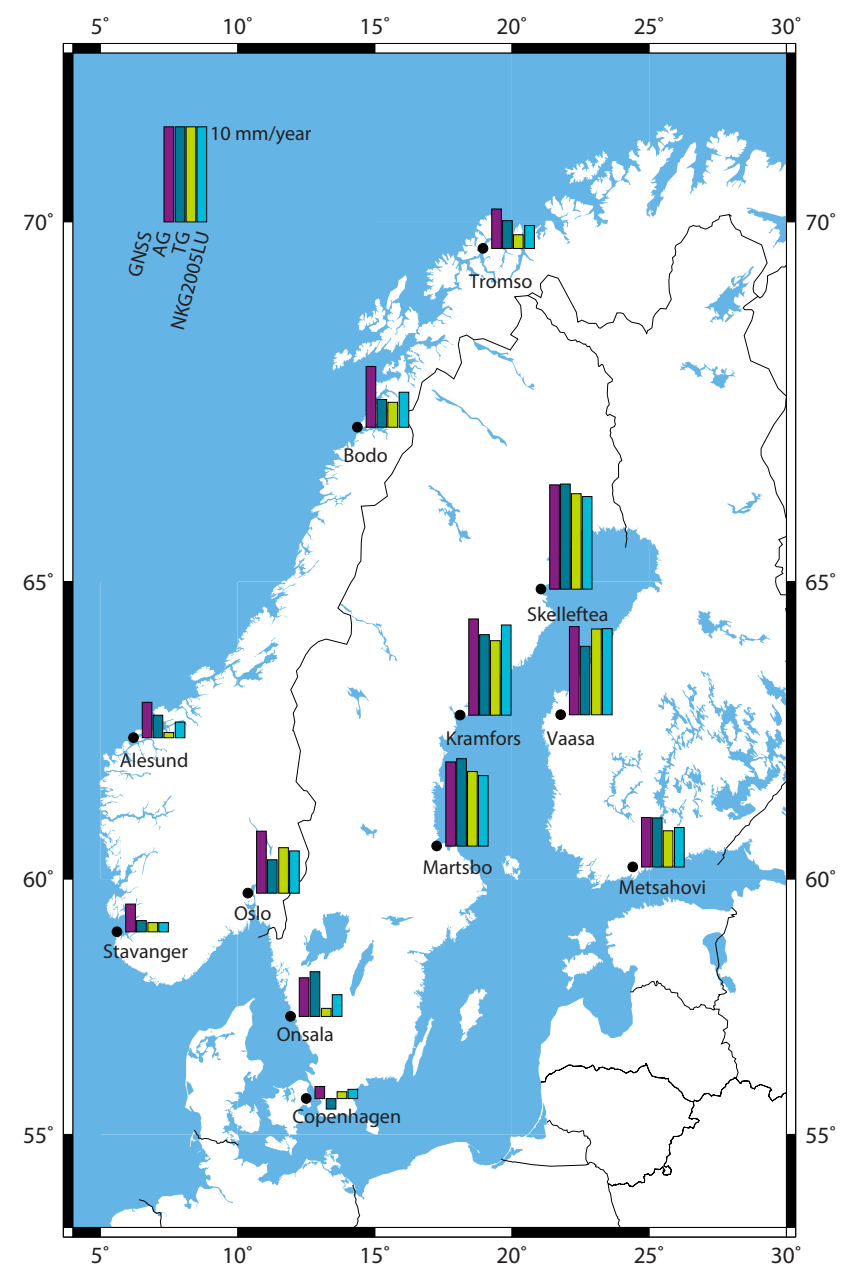

Figure 3. Land uplift values with the sea level rise estimate of $1.32 \mathrm{~mm} \mathrm{yr}^{-1}$ (Table 2).

where $\dot{H}_{\mathrm{e}}$ is the mean sea level rise, $\dot{h}_{i}$ is the absolute land uplift value from GNSS, $\dot{H}_{a, i}$ is the apparent sea level change from tide gauge data (Table 1 ) and $n$ is the number of stations. The value 0.94 scales the GNSS-derived uplift value for the $6 \%$ geoid rise (Ekman and Mäkinen, 1996). We obtain the value for $\dot{H}_{\mathrm{e}}=3.11 \pm 1.07 \mathrm{~mm} \mathrm{yr}^{-1}$, which agrees with the contemporary sea level rise values from satellite altimetry (e.g. Cazenave and Llovel, 2010). Table 3 shows the values of land uplift using the value for sea level rise computed above. The standard deviations vary from 0.3 to 1.8 . The mean of the standard deviations diminishes from 1.1 to $0.99 \mathrm{~mm} \mathrm{yr}^{-1}$, which is not surprising, since a mean value computed with this data set was used. The values of Table 3 are depicted in Fig. 4.

A comparison of techniques is challenging since they measure height relative to a different reference level and conversions are needed to bring all measurements to the same system. Stations with multiple techniques can be used to study the differences and similarities of the measurement techniques, since different techniques are affected by differ-

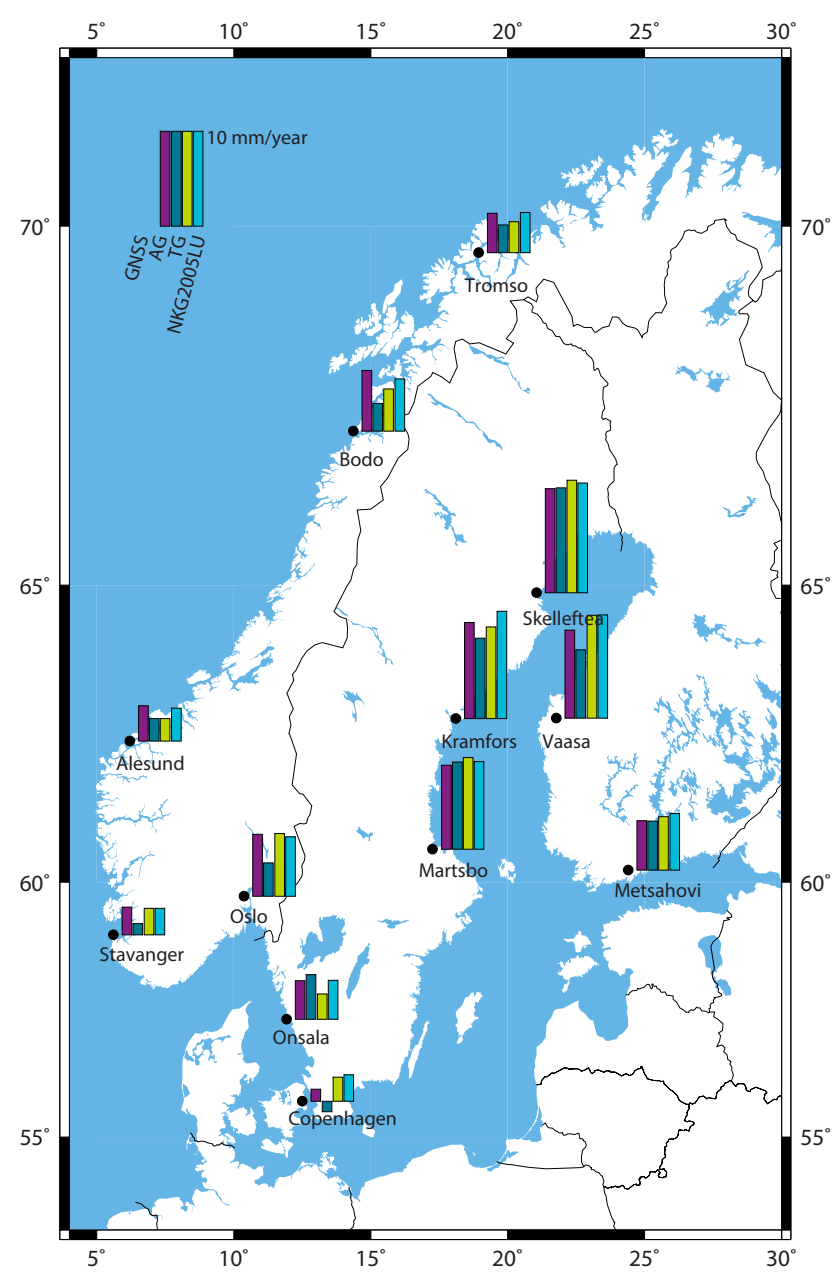

Figure 4. Land uplift values with sea level rise estimate of $3.11 \mathrm{~mm} \mathrm{yr}^{-1}$ (Table 3).

ent geophysical processes. GNSS observes ellipsoidal height change, whereas a gravimeter observes gravity change due to the height change and redistribution of masses, and tide gauge data are affected by the sea level change and the local uplift. The GNSS uses the centre of the figure (CF) of Earth (which is at these timescales equivalent to centre of the entire Earth frame (CE)) and is able to observe and monitor the Earth's centre of mass, whereas the absolute gravity measurements are done in the centre of mass frame (CM). Also worth noting is that the z-translation rate of the reference frame has a larger impact on the vertical component at these high latitudes.

We made a comparison using the values of 12 selected stations in Table 3. The first item is to find a plausible estimate for the sea level rise because it is required to transform the tide gauge values into same reference level as the GNSS data. The value strongly depends on the time span of our time series. The global sea level rise is currently accelerating and thus the selection of the time series length used to estimate the rise may play an important role. If the trend of sea level 
is computed for the same period of time that GNSS has been in operation (last 20 years), the values differ markedly from the values of the whole tide gauge record. There might also be large spatial differences, since, e.g. the melt waters from glaciers are not distributed equally on Earth (Tamisiea et al., 2001).

The estimates of global sea level rise for the last century vary between 1 and $1.8 \mathrm{~mm} \mathrm{yr}^{-1}$ (Church et al., 2013), depending slightly on the time window. Similar values were obtained for the Baltic Sea (Johansson, et al., 2003) but the question remains whether the same global sea level rise value can be used for the Norwegian coast as for the Baltic. The Baltic Sea is a semi-closed basin where the effect of the North Atlantic Oscillation (NAO) (e.g. Johansson, et al., 2003, 2004) and the effect of the meridional wind (Johansson M. et al., 2012) is noticeable. The strength of prevailing westerly winds will push less or more water through the Danish straits; thus causing decadal variation of the sea level rise in the Baltic, following the general trend of the NAO index. In general, the Baltic sea follows the sea level rise of the North Sea and North Atlantic, but decadal anomalies can exist as discussed in Johansson et al. (2003).

In the NKG2005LU model, Vestøl (2005) used the value of $1.32 \mathrm{~mm} \mathrm{yr}^{-1}$ for the sea level rise, which was the best estimate for the Baltic Sea in the period 1891-1990 (the value used in Table 2). From satellite altimetry the sea level rise of the last decade is about $3 \mathrm{~mm} \mathrm{yr}^{-1}$ (Cazenave and Llovel, 2010; Church and White 2011, Johansson et al., 2012). Using the values in Table 1 and Eq. (3) we computed the sea level rise based on the 12 stations in our example. The value of $3 \mathrm{~mm} \mathrm{yr}^{-1}$ coincides well with the global value given by Cazenave and Llovel (2010). This value is used in Table 3.

The absolute gravity measurements are very sensitive to environmental changes (nearby sea, groundwater, etc.). In many cases, the AG time series may contain only a few observations. Therefore, the difference in the trend estimate from either short or long time series can be significant and any anomalous observation may affect the trend. This can be seen in the case of Onsala and Copenhagen, where changes in the sea level of the Danish straits affect the measurements noticeably (Müller et al., 2010; Timmen et al., 2011).

In Table 3 all standard deviations greater than 1 are coming from cases where the gravity-based values are deviating from the three other techniques. We computed also the case where the AG observations were neglected (last two columns in Table 3). As one can see, the standard deviation diminished significantly, from the mean value of 0.99 to 0.60 . More data are needed to make a final conclusion, in general, on the usefulness and reliability of the AG time series, as the length of the time series used in the present study are only 4 (Breili, 2009) or 5 years (Gitlein, 2010), and the measurements are prone to local effects, as discussed above.

In data processing, problems may also stem from the use of different theoretical models. For example, for both GNSS and gravity computations, the solid Earth tide and ocean tidal loading are taken into account. Differences in these models' reference frames have been shown to produce spurious signals in GNSS computation (Fu et al., 2012). Also different handling of the solid earth tide in these two specific cases may produce a latitude-dependent bias (Poutanen et al., 1996).

Another theoretical aspect is that the gravity values were transformed using the rate of $-0.17 \mu \mathrm{Gal} \mathrm{mm}{ }^{-1}$. This value has been argued in the literature (Wahr et al., 1995; Ekman and Mäkinen, 1996; Mäkinen et al., 2005; Gitlein, 2010). It is a modest approximation, but not necessarily the optimum one. When more gravity data are processed and values also from the subsiding areas are used, the accuracy of the ratio will most likely improve (Mäkinen et al., 2005).

In this study, we have shown that data comparisons are needed to exploit the full potential of the geodetic networks. To fully utilize the potential of different techniques and measurements and to avoid problems with different models chosen for data handling, all data should be processed for the same time period and using the same models.

One concern with this type of review study is that the user has no control over the observations or data reduction. The authors of the published results have chosen the best observations and models for their study. Thus, the values need to be taken as they are and trust that differences in data selection and processing do not distort the comparison markedly. In order to make comparisons possible and reliable, researchers should document in detail what they have done. Such information can nowadays be easily embedded into appendixes or other electronically saved background information. Such information should be available in the database.

\section{Conclusions}

During the last decade, geodesists have proposed and developed regional and global observing systems with several observing techniques at the same site, databases, and combinations of different observing techniques. In Nordic countries, the proposed observing system NGOS, organized by the NKG, includes stations in the Nordic countries and Baltic states up to Iceland and Greenland. The first goal of this study was to create a simple database offering access to the network stations and the related data. This was realized by collecting available information and providing an interface with metadata and relevant links to the users.

The second goal was to demonstrate the use of the database in geodetic studies. Here we carried out land uplift studies using a set of coastal geodetic stations and compiled uplift values obtained by three techniques: GNSS, TG, AG. The results were then compared to the NKG2005LU land uplift model to estimate values for the present day uplift. We conclude that the best compatibility is obtained between continuously measuring techniques, i.e. continuous GNSS and tide gauges. The outcomes of these techniques are difficult to 
compare because they measure different processes and their reference levels are not the same. More work is needed to solve this issue more reliably.

Integrity and reliability are essential when combining multi-technique data; they involve standardized techniques to process the original observations, unified models, and accessible original data and background information. The use of geodetic observing systems is a way to achieve this goal.

\section{The Supplement related to this article is available online at doi:10.5194/se-5-673-2014-supplement.}

Special Issue: "Lithosphere-cryosphere interactions"

Edited by: M. Poutanen, B. Vermeersen, V. Klemann, and C. Pascal

\section{References}

Ågren, J. and Svensson, R.: Postglacial Land Uplift Model and System Definition for the New Swedish Height System RH 2000. LMV-Rapport 2007:4. Reports in Geodesy and Geographical Information Systems, Gävle, ISSN 280-5731, 2007.

Breili, K.: Investigations of surface loads of the Earth - geometrical deformations and gravity changes, Ph.D. Thesis, Department of Mathematical Sciences and Technology, Norwegian University of Life Sciences, vol. 2009:25, ISSN 1503-1667, ISBN 978-82575-0892-0, 2009.

Cazenave, A. and Llovel, W.: Contemporary sea level rise, Annu. Rev. Mar. Sci., 2, 145-173, doi:10.1146/annurev-marine120308-081105, 2010.

Church, J. and White, N.: Sea-level rise from the late 19th to the early 21st century, Surv. Geophys., 32, 585-602, doi:10.1007/s10712-011-9119-1, ISSN 0169-3298, 2011.

Church, J. A., Clark, P. U., Cazenave, A., Gregory, J. M., Jevrejeva, S., Levermann, A., Merrifield, M. A., Milne, G. A., Nerem, R. S., Nunn, P. D., Payne, A. J., Pfeffer, W. T., Stammer, D., and Unnikrishnan, A. S.: Sea Level Change, in: Climate Change 2013: The Physical Science Basis. Contribution of Working Group I to the Fifth Assessment Report of the Intergovernmental Panel on Climate Change, edited by: Stocker, T. F., Qin, D., Plattner, G.K., Tignor, M., Allen, S. K., Boschung, J., Nauels, A., Xia, Y., Bex, V., and Midgley, P. M., Cambridge University Press, Cambridge, United Kingdom and New York, NY, USA, 2013.

Ekman, M.: A consistent map of the postglacial uplift of Fennoscandia. Terra Nova, 8, 158-165, 1996.

Ekman, M.: Postglacial uplift rates for reducing vertical positions in geodetic reference systems, in: Proceedings of the General Assembly of the Nordic Geodetic Commission, 401-407, ISSN 0280-5731, 1998.

Ekman, M. and Mäkinen, J.: Recent postglacial rebound, gravity change and mantle flow in Fennoscandia, Geophys. J. Int., 126, 229-234, doi:10.1111/j.1365-246X.1996.tb05281.x, 1996.

Fu, Y., Freymueller J. T., and van Dam, T.: The effect of using inconsistent ocean tidal loading models on GPS coordinate solutions, J. Geod., 86, 409-421, doi:10.1007/s00190-011-0528-1, 2012.
Gitlein, O.: Absolutgravimetrische Bestimmung der fennoskandischen Landhebung mit dem FG5-220, Wissenschaftliche Arbeiten der Fachrichtung Geodäsie und Geoinformatik der Leibniz Universität Hannover, vol. 2009:281, ISSN 0174-1454, ISSN 00655325, ISBN 978-3-7696-5055-6, 2010.

Gross, R. and Poutanen, M.: Geodetic Observations of Glacial Isostatic Adjustment. EOS, 90, No. 41, 365, 2009.

Ihde, J., Baker, T., Bruynix, C., Francis, O., Amalvict, M., Kenyeres, A., Mäkinen, J., Shipman, S., Simek, J., and Wilmes, H.: Concept and Status of the ECGN Project, in: EUREF Publication, Symposium Toledo, 4-7 June 2003, in: Mitteilungen des Bundesamtes für Kartographie und Geodäsie, vol. 12:33, Frankfurt a.M., 57-65, 2004.

Johansson, J. M., Davis, J. L., Scherneck, H.-G., Milne, G. A., Vermeer, M., Mitrovica, J. X., Bennett, R. A., Jonsson, B., Elgered, G., Elósegui, P., Koivula, H., Poutanen, M., Rönnäng, B. O., and Shapiro, I. I.: Continuous GPS measurements of postglacial adjustment in Fennoscandia. 1. Geodetic results, J. Geophys. Res.-Sol. Earth, 107, 1978-2012, doi:10.1029/2001JB000400, 2002.

Johansson, M., Kahma, K., and Boman, H.: An improved estimate for the long-term mean sea level on the Finnish coast, Geophysica, 39, 51-73, 2003.

Johansson, M., Kahma, K., Boman, H., and Launiainen, J.: Scenarios for sea level on the Finnish coast, Boreal Environ. Res., 9, 153-166, 2004.

Johansson, M., Pellikka, H., Kahma K., and Ruosteenoja, K.: Global sea level rise scenarios adapted to the Finnish coast, J. Mar. Syst., 129, 35-46, doi:10.1016/j.jmarsys.2012.08.007, 2012.

Kairus, A.: Pohjoismaisen geodeettisen havaintojärjestelmän käyttö maannousututkimuksessa (using the Nordic Geodetic Observing System for Land Uplift Studies), Master's thesis, Aalto University, 51 pp., 2012 (in Finnish).

Lambeck, K., Smither, C., and Ekman, M.: Test of glacial rebound models for Fennoscandia based on instrumented sea- and lakelevel records, Geophys. J. Int., 135, 375-387, 1998.

Lidberg M.: Motions in the Geodetic Reference Frames - GPS observations. Technical Report No. 517, Licentiate Thesis. Department of Radio and Space Science with Onsala Space Observatory, Chamlers University of Technology, Göteborg, 2004.

Lidberg, M., Johansson, J. M., Scherneck, H. G., and Davis, J. L.: An improved and extended GPS-derived 3-D velocity field of the glacial isostatic adjustment (GIA) in Fennoscandia, J. Geod., 81, 213-230. doi:10.1007/s00190-006-0102-4, 2007.

Lidberg, M., Johansson, J. M., Scherneck, H. G., and Milne, G. A.: Recent results based on continuous GPS observations of the GIA process in Fennoscandia from BIFROST, J. Geodyn., 50, 8-18, 2010.

Mäkinen, J., Engfeld, A., Harsson, B. G., Ruotsalainen, H., Strykowski, G., Oja, T., and Wolf, D.: The Fennoscandian land uplift lines 1966-2003, in: Gravity, Geoid and Space Missions GGSM2004, IAG Symposium, vol. 129, Springer, Berlin Heidelberg, 328-332, 2005.

Müller, J., Naeimi, M., Gitlein, O., Timmen, L., and Denker, H.: A land uplift model in Fennoscandia combining GRACE and absolute gravimetry data, Phys. Chem. Earth, 53, 54-60, doi:10.1016/j.pce.2010.12.006, 2010. 
Pettersen, B.: The postglacial rebound signal of Fennoscandia observed by absolute gravimetry, GPS, and tide gauges, Int. J. Geophys., 2011, 957329, doi:10.1155/2011/957329, 2011.

Peltier, W. R.: Global glacial isostasy and the surface of the ice-age Earth: the ICE-5G(VM2) model and GRACE, Annu. Rev. Earth Pl. Sc., 32, 111-149, 2004.

Peltier, W. R.: Postglacial variations in the level of the sea: implications for climate dynamics and solid-earth geophysics, Rev. Geophys., 36, 603-689, 1998.

Plag, H. P. and Pearlman, M. (Eds.): Global Geodetic Observing System: Meeting the Requirements of a Global Society on a Changing Planet in 2020, Springer, doi:10.1007/978-3-64202687-4, ISBN 978-3-642-02686-7, 2009.

Poutanen, M., Dransch, D., Gregersen, S., Haubrock, E. R. I., Klemann, V., Kozlovskaya, E., Kukkonen, I., Lund, B., Lunkka, J. P., Milne, G., Müller, J., Pascal C., Pettersen, B. R., Scherneck, H. G., Steffen, H., Vermeersen, B., and Wolf, D.: DynaQlim - upper mantle dynamics and quaternary climate in cratonic areas, in: New Frontiers in Integrated Solid Earth Sciences, edited by: Cloetingh, S. and Negendank, J., Springer, 349-372, doi:10.1007/978-90-481-2737-5_10, 2010.

Poutanen, M., Ihde, J., Bruyninx, C., Francis, O., Kallio, U., Kenyeres, A., Liebsch, G., Mäkinen, J., Shipman, S., Simek, J., Williams, S., and Wilmes, H.: Future and development of the European Combined Geodetic Network ECGN, Earth on the Edge: Science for a Sustainable Planet, Proceedings of the 2011 IAG General Assembly, Melbourne, Australia, edited by: Rizos, C. and Willis, P., International Association of Geodesy Symposia Vol. 139, 121-127, Springer, 2014.

Poutanen, M. and Ivins, E. R.: Upper Mantle Dynamics and Quaternary Climate in Cratonic Areas (DynaQlim) - understanding the Glacial Isostatic Adjustment, J. Geodyn., 50, 2-7, doi:10.1016/j.jog.2010.01.014, 2010.
Poutanen M., Knudsen, P., Lilje, M., Nørbech, T., Plag, H.-P., and Scherneck, H.-G.: The Nordic Geodetic Observing System (NGOS), in: Dynamic Planet - Monitoring and Understanding a Dynamic Planet with Geodetic and Oceanographic Tools, Conference of the International Association of Geodesy, Cairns, Australia, 22-26 August 2005, vol. 130, edited by: Rizos, C. and Tregoning, P., International Association of Geodesy Symposia, 749-756, 2007.

Poutanen, M., Knudsen, P., Lilje, M., Nørbech, T., Plag, H. P., and Scherneck, H. G.: NGOS - the Nordic Geodetic Observing System, Nord. J. Surv. Real Est. Res., 2, 79-100, 2005.

Poutanen M., Vermeer, M., and Mäkinen, J.: The permanent tide in GPS positioning, J. Geod., 70, 499-504. doi:10.1007/BF00863622, 1996.

Tamisiea, M., Mitrovica, J., Milne, G. A., and Davis J.: Global geoid and sea level changes due to present-day ice mass fluctuations, J. Geophys. Res.-Sol. Ea., 106, 30849-30864, 2001.

Timmen, L., Gitlein, O., Klemann, V., and Wolf, D.: Observing gravity change in the Fennoscandian uplift area with the Hanover absolute gravimeter, Pure Appl. Geophys., 196, 13311342, doi:10.1007/s00024-011-0397-9, 2011.

van Dam, T., Visser, P., Sneeuw, N., Losch, M., Gruber, T., Bamber, J., Bierkens, M., King, M. and Smit, M.: Monitoring and modeling individual sources of mass distribution and transport in the Earth system by means of satellites. Final Report, ESA Contract 20403, 2008.

Vestøl, O.: Determination of postglacial land uplift in Fennoscandia from leveling, tide-gauges and continuous GPS stations using least squares collocation, J. Geod., 80, 248-258, doi:10.1007/s00190-006-0063-7, 2005.

Wahr, J. M., Dazhong, H., and Trupin, A.: Predictions of vertical uplift caused by changing polar ice volumes on a viscoelastic Earth, Geophys. Res. Lett., 22, 977-980, 1995.

Woodworth, P. L. and Player, R.: The permanent service for mean sea level: an update to the 21st century, J. Coastal Res., 19, 287 295, ISSN 0749-0208, 2003. 